\title{
UTILIZATION OF COMPUTER SIMULATION FOR WASTE SEPARATION DESIGN AS A LOGISTICS SYSTEM
}

\author{
Straka, M. ; Khouri, S. ${ }^{* *}$; Rosova, A. ; Caganova, D. ${ }^{* * *} \&$ Culkova, K. ${ }^{* *}$ \\ *Institute of Logistics, BERG Faculty, Technical University of Kosice, Park Komenskeho 14, 04384 \\ Kosice, Slovakia \\ ** Institute of Earth Resources, BERG Faculty, Technical University of Kosice, Park Komenskeho 19, \\ 04384 Kosice, Slovakia \\ ${ }^{* * *}$ Institute of Industrial Engineering and Management, Faculty of Materials Science and Technology \\ in Trnava, Slovak University of Technology in Bratislava, Pavilón T02-110, J. Bottu 25, 91724 \\ Trnava, Slovakia \\ E-Mail: martin.straka@tuke.sk, samer.khouri@tuke.sk, andrea.rosova@tuke.sk, \\ dagmar.caganova@stuba.sk, katarina.culkova@tuke.sk
}

\begin{abstract}
The article discusses the problem of total waste separation in the frame of a computer simulation design of these systems. The aim of the article is to employ computer simulation, modelling and logistics for the needs of total separation of waste and its recycling into the form of raw materials and re-usable resources in practice. The results of the computer simulation show that by using total separation and waste recycling in the specifically analysed region, it is possible to produce approximately 7700 tons of recycled paper, 2400 tons of multilevel packages, 8000 tons of glass, 3000 tons of old textiles, 3500 tons of iron, approximately 1500 tons of non-ferrous metals, approximately 2700 tons of wooden pallets, approximately 1200 tons of rubber granulate, to process approximately 800 tons of dangerous waste, 2400 tons of electro waste, 2100 tons of gravel, 840 tons of sand and to liquidate approximately 3200 tons of non-recyclable waste during the whole year.

(Received in March 2018, accepted in June 2018. This paper was with the authors 1 week for 1 revision.)
\end{abstract}

Key Words: Computer Simulation, EXTENDSIM, Waste Separation, Logistics, Design

\section{INTRODUCTION}

Let us forget the incineration of waste as a means of the first possible solution of the waste disposal, and let us merely use it as a means of the last option for the waste disposal solutions. The first waste disposal solution within this paper will be "total waste separation" and its maximum possible secondary recovery. Waste treatment will be seen as a net production without or with a minimum of waste incineration (only those that are hazardous and nonrecyclable) reusable starting materials. To achieve the desired state of maximum recovery of waste is necessary to use available technology as well as logistics and its principles as a means of managing flows. According to the Council of Supply Chain Management Professionals [1] „Logistics management is the part of supply chain management that plans, implements, and efficiently controls the forward and reverse flow, and storage of goods, services and related information between the point of origin and the point of consumption in order to meet customers' requirements. Logistics management is an integrating function, which coordinates and optimizes all logistics activities, as well as integrates logistics activities with other functions including marketing, sales manufacturing, finance, and information technology."

From all this being discussed, a number of questions arise:

- How will the company for Total separation and treatment look like?

- Will such an enterprise be able to process the required quantities of shipped waste?

- What will be the production of raw materials from waste recycling? 
Given that building-up such an authentic, complex and comprehensive enterprise for total waste treatment is time-consuming and financially demanding, to solve our requirements, a simulation model will be created that will work with real data, which are derived from the statistics of the actual operation of waste incineration plants in a particular region in Slovakia. In reality, to ensure the same planned action for the total waste separation and its recovery, it is possible to use existing workplaces in the region. Even if these do not form an entire company, with the help of logistics and transport, it is possible to create a functional network of smaller plants that would fulfil the same activity objective as a significant entity, a single company. The problem, which the article examines, is related to the use of logistics, modelling, and simulation for the needs of the conditioned total separation and total use of waste as a source of secondary raw materials in a particular region of the Slovak Republic.

\section{METHODOLOGICAL BASE}

Flow management and logistics in the waste processing can be classified into several levels. The first level is created for the recycling needs of the waste collection logistics chain. The second level is formed by the logistics of the production, i.e., flow management in the process of implementing waste recovery. The third level is created by the logistics of the "finished product", i.e., the distribution of primary and recycled raw material for the needs of new production, for instance paper, plastics, textiles, and metals.

\subsection{Logistics and computer simulation as the base of the solution}

Solid waste management is a set of consistent and systematic regulations related to control generation, storage, collection, transportation, processing, and landfilling of wastes according to the best public health principles, economy, preservation of resources, aesthetics, other environmental requirements, and what the public attends to [2,3]. The focus on recovery of resources, recycling and reuse can be described as "cradle-to-cradle" resource management [4]. According to the authors Vidalakis and Tookey [5], Matwiejczuk [6] and Loučanová et al. [7] logistical processes have to be fully understood in the context of the built environment. In this context, physical, thermal, and chemical recycling technologies are the most widely used [8]. Waste separation is a critical component of a successful integrated waste management system $[9,10]$. Waste separation increases the quality of produced compost and recyclables, and optimizes incineration. It also enables better financing of waste management activities and minimizes the energy and labour inputs to any downstream processes $[11,12]$.

One of the available approaches that can be used within the methodological apparatus of logistics to analyse, research and to streamline processes is the computer simulation. According to the authors Ahluwalia and Nema [13] is the configuration of computer waste management facilities is important for achieving of a defined target. Simulation is used in stochastic and dynamic contexts in order to identify patterns and tendencies, which is often more essential than finding an optimal solution [14-18]. According to authors like Delgado Sobrino et al. [19] and Kliment and Trebuňa [20] simulation is able to overcome most of the shortcomings of analytical methods, but it is very often more demanding in terms of time (model design and testing, planning and realization of experiments, etc.), besides the preparation of input data is also more expensive and time-consuming. On the other hand, a detailed simulation model cannot be possibly designed without the cooperation and partnership from practice [21-23]. Design and the development of simulation models is a valuable tool for prediction of the performance of production systems [24-28]. The simulation modelling is however not a tool to achieve optimal solutions, but instead a tool that allows to test different outputs decision on the simulation model [29-32]. On the other side of things, waste reduction is one of the basic concepts of lean thinking. By simulation is possible to 
verify these considerations [33]. According to the author Kleijnen [34] simulation gives a significant insight into the cause and effect relations of the supply chain performance. Such system analysis computer simulations also addresses the conditions that are extreme, unlikely or impossible, dangerous for the studied systems, people, nature, the environment, and where in reality it would not be possible to breach the defined standards. This makes it possible to understand the system operation also in risk conditions of risk and with certain probability estimate the behaviour of the system, or to define procedures that under certain ecological status must be implemented.

\subsection{Data for the computer simulation waste total separation design}

The current input is formed by tying thousands of tons of garbage from the city of Kosice and its surroundings. The current, core activity of the chemical company will be changed by simulation of utter waste incineration to all-out waste separation.

After a thorough analysis of the system of the processing company's activities, the following findings arise:

- 83000 tons of waste imported in the company every year, which passes through several processing treatments.

- Approximately $19 \%$ of the plastic and electrical components, and $10 \%$ is wood in various forms, and more than $71 \%$ of miscellaneous municipal waste is formed out of the total volume of imported waste.

- The result / product of the incineration process and separation is approximately $3 \%$ ash, $90 \%$ of incinerated waste and about $7 \%$ are gases that arise in the process of waste incineration. The gases pass through the filtration step, and the total volume of the flue gases consists of $65 \%$ water vapour and $35 \%$ of the emissions.

- The volume is separated by a charred mass of more than $2 \%$ metals and $98 \%$ of the net clinker. Breeze needs to cool by adding water. $10000 \mathrm{~m}^{3}$ of water is used to cool the clinker every year. The cooled slag is stored in a landfill within the enterprise.

Data obtained from the analysis of a particular activity on waste incineration is important to set the input parameters of the simulation model. Important and significant changes in the activity of the company lie on changing utter burning for all-out waste separation. Other parts of the company will be processing plastics granules, biogas plant to produce digestate and biogas, paper recycling, treatment of multi-layer packaging, processing, glass, textiles, briquetting metal pelletizing wood granulation rubber storage of hazardous waste, processing of e-waste processing of inorganic waste, and disposal of non-recyclable waste.

The largest percentage of municipal waste is represented by biodegradable waste. It is necessary to sort out waste of all packaging, bags and other containers where this may be located. Up to $35 \%$ of biological waste can be recovered in a biogas plant. The department for processing bio waste us biodegradable waste to produce biogas and fertilizer in the form of digestate. During the separation, organic waste passes through the waste tray in which portions of the mixture are prepared for processing.

The dose of biodegradable waste enters the digester in which it breaks during a specified period, while generating biogas which contain methane component. The amount of the produced biogas is dependent on the quality and composition of the biomass. As a general rule, $25-900 \mathrm{~m}^{3}$ of biogas can be produced out of a ton of biomass, depending on the quality, and composition of the biomass. Fermenter recovered waste is used as a fertilizer for agricultural purposes. The calorific value of biogas is around 20 to $25 \mathrm{MJ} / \mathrm{m}^{3}$. One $\mathrm{m}^{3}$ of biogas contains as much energy as 0.6 to 0.7 litres of fuel oil.

Up to $17 \%$ of paper from municipal waste is directly recyclable after the separation. For every 1.6 tons of sorted paper another 1.0 ton of recycled paper can be obtained. Sift old paper tray is stored in old paper. Other operations that make up the technological process are 
Breaking the fiber - Pulping - Separation and cleaning - Thickening - Creating sheets of paper. The paper sheet is in the form of paper rolls that are ready for further processing. The whole technological process forms the process of the old paper recycling.

Currently, popular multi-layered covers form a $3 \%$ of the total municipal waste. They are transferred for crushing and tearing up after the separation from the multilayer stack of materials. The material is gradually rid of paper, plastic film, aluminium foil, and printing inks. The components travel through the processing according to the type of separation. The basic multi-layer material can be used for the production of building board (patented by KURUC company, Slovakia), or raw materials can be used for paper, plastic, and aluminium by separation.

An interesting part of the recycling is formed of glass waste. Its advantage is that it can be $100 \%$ assessed, virtually without limitations. Glass is sorted by colour, and white glass must be free of closures and other metal elements. Contaminants and metals are sorted out before recycling. The total amount of municipal waste glass is $10 \%$. It is mixed from ready cullet with the batch 40/60, respectively 50/50. That is, the production of 1 ton of the new glass is formed out of $500 \mathrm{~kg}$ cullet, and $500 \mathrm{~kg}$ batch. The entire batch is melted at a high temperature of about $1400-1600{ }^{\circ} \mathrm{C}$.

Another ingredient of the strapped municipal waste consists of textiles. The textile is $4 \%$ of the total amount of municipal waste. After separation, the textiles are stored in the tray from which they are being transferred to the blasting of textiles. After tearing the fabric, it is prepared for further processing which is needed for the production of building elements and insulation.

An integral part of the municipal waste is metals. The metals represent $4 \%$ of the total volume of municipal waste. After the primary separation, they are divided into ferrous and non-ferrous metals. And ferrous and non-ferrous metals are torn and shredded into smaller pieces, followed by briquetting as the final product after separation. Metal briquettes are batch for the production of iron and steel, respectively for aluminium, copper, and the like. Metals can be continuously recycled again.

The wood and gum form $5 \%$ of the total volume of municipal waste. After sorting, the wood pellets are produced from wood. Rubber is crushed into rubber granules.

Part of the municipal waste is $1 \%$ of hazardous waste and $4 \%$ of non-recyclable waste. Both types of waste are usually disposed of by incineration at high temperatures, respectively storage in special landfills. The simulation model will deal with non-recyclable waste incineration but not hazardous waste that needs to be landfilled.

For disposal in municipal waste, it receives the amount of electronic waste, which accounts for $3 \%$ of the total. Electronic waste is crushed, shredded and sorted on a table into plastic, metal and electronic dust.

The municipal waste contains many stone minor construction waste and sand. Inorganic waste constitutes $4 \%$ of the total municipal waste. It is graded into sand and gravel on separation sieves.

\section{CASE STUDY}

Separation and recycling of waste have their system and exact process. From the information mentioned above and based on the analysis of the activities, it is possible to construct a formalized scheme of total separation and total waste recycling (see Fig. 1). The formalized scheme represents a complex system with its elements and relations. The elements of the system form individual parts and operations with the waste. Among the individual operations there are relations created by elements of transport, management of waste flow and rising separated materials, such as plastic, biologic waste, paper, multilayer material, glass, textile, 
metals, wood, gum, dangerous waste, electro material, inorganic waste, and no recycling waste. The main goal in the frame of the researched system is monitoring the amount of secondary produced raw material and the systematic demands on production for the particular region in Slovakia.

\subsection{A formalized scheme and block diagram of the waste total recycling}

The constructed formalized scheme represents an important base for the creation of single simulation model. Individual parts of the formalized scheme are consequently replaced by correspondent blocks of a particular simulation system. The creation of the simulation model consists of two parts.

The first part lies on the representation of the correspondent simulation system by using a block scheme (see Fig. 2).

The second part presents single simulation model with the realization of the research for the area of total separation and total recycling of the waste (see Fig. 3).

The construction of the block scheme, as a foundation for the single simulation model, is essential for data and information preparation that will be the base for the setting of individual blocks of the simulation model.

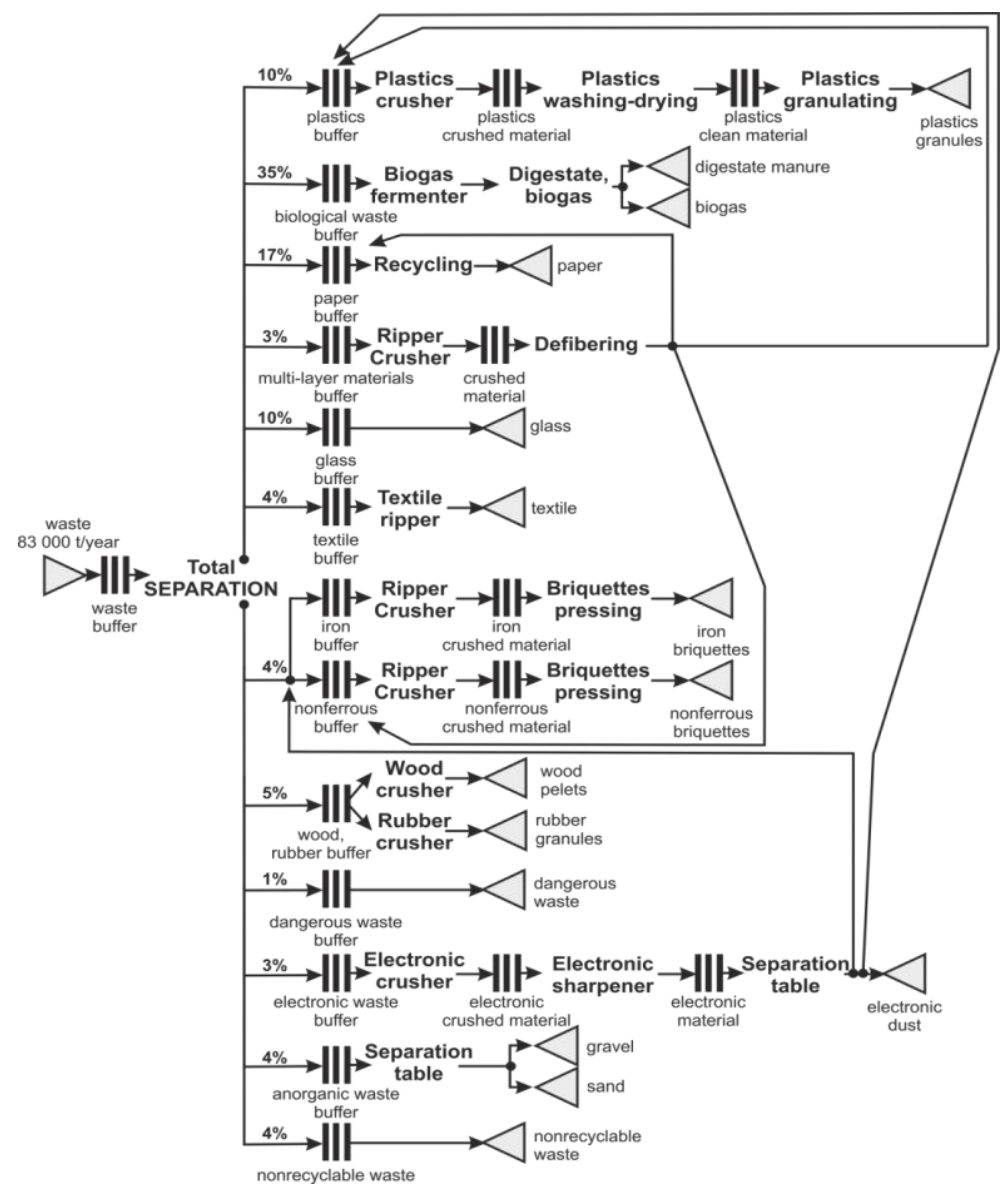

Figure 1: Formalized scheme of the company's activity for total separation and total recycling of waste.

The statistical data obtained from the case study company from the area of Kosice surroundings, Koksov - Baksa shows that the amount of waste supply into the company complex is 83000 tons per year. The input waste is temporarily disposed on a landfill from which it is further processed. The landfill is represented by the block "Queue" (see Fig. 2).

Then the total separation follows and the sorting of waste for the needs of so-called total recycling of all available raw material in waste. A given activity is provided from the point of 
view of simulation by block "Select item out". According to percentage representation of the elements in the waste, the block will separate and transport waste elements to the individual workplaces, orientated to processing, preparation, and modification of particular waste elements in the form of basic raw material or an intermediate product for further processing.

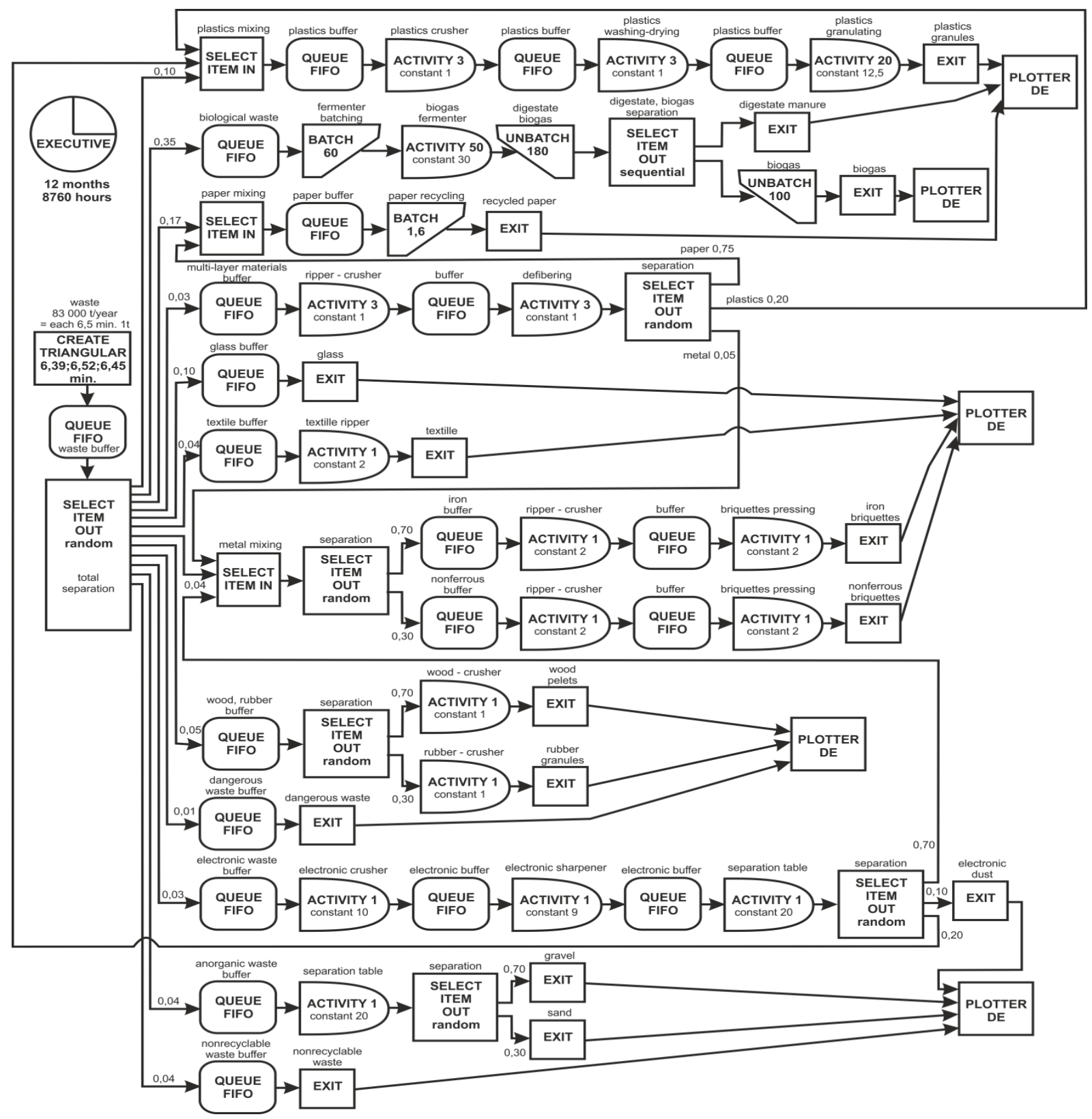

Figure 2: Block scheme for the simulation system EXTENDSIM representing the activities of total separation and total recycling of waste in the frame of the analysed company.

According to technological process, the workplace for plastic recycling consists of stocks for separated plastics, plastic crushing, stocks for crushed plastics, cleaning and drying of plastic, re-granulator and stocks for recycling plastics granules. In the frame of simulation system EXTENDSIM, there is given the process of technology, created by the combination of blocks "Queue" and "Activity". The block "Queue" represents stock for given part of technological process and the block "Activity" represents equipment and operation that is realized in a particular part. Delaying, length of operations realization and number of equipment are presented by technology and capacity of equipment that are prescribed by 
equipment producers. The bock "Exit" records the total number of produced plastic granulates.

According to technologic process, the workplace for biologic waste processing is the created by stocking for biologic waste, fermenter, and production of fertilizer and biogas digestate. There is given succession of technology in the frame of simulation system, which is created by the block "Queue" succession - stocking of biologically decomposable waste, "Batch" - preparation of biogas batch, "Activity - Unbatch" - fermenter, production of biogas and digestate, "Select item out" - separation of biogas from digestate, "Exist" volume of produced digestate and "Unbatch - Exit" - volume of produced biogas. Delaying, length of realization of digestate and biogas production, number and capacities of equipment are given by technology, which is prescribed by producers and presents around 25-30 days for biomass batching.

In the workplace for paper recycling a stock of old paper is created, this is represented by the block "Queue", technology for old paper recycling, representing by the block "Batch" and block "Exit" - the volume of produced paper.

The workplace for multilayer packages recycling creates a reservoir of separated multilayer packages, presented by the block "Queue", crushing and tearing of packages, represented by the block "Activity", reservoir before operation of pulping and single pulping. Given activities are provided by the blocks "Queue" and "Activity". Separated materials are separated to paper, plastic, and metals. In given rate elements of multilayer, packages are transported to the correspondent workplaces.

Workplace for glass recycling is created by a reservoir for separated glass, the block "Queue". Glass splinters present important part for preparation of glass element. After separation, the material is exported by an external company that deals with the production of glass products. The practically whole volume of waste glass can be repeatedly elaborated. The volume of produced glass is recorded through the block "Exit".

Workplace for textile recycling presents reservoir for textile, the block "Queue". Textile is tearing in tearing equipment to fibres, pieces that are packed into the packages, exported by an external company for further processing. The production and export of textile material are presented in the simulation model by the blocks "Activity - Exit".

The workplace for metal waste processing is created by waste separation into iron waste and non-ferrous metals. This activity is represented in the simulation model by the block "Select item out". Separated metals are stored in correspondent reservoirs that are represented in the simulation by the block "Queue". Tearing, pruning and crushing to smaller parts continue and mentioned operations process to the briquette equipment. The output is iron and non-ferrous briquettes that are exported by an external company. These given activities represent the connection of the blocks "Queue - Activity - Exit".

A further element of waste is wood and gum that are individually crushed and torn on the correspondent equipment. The output is wooden pellets and granulates from the gum. Wooden pellets and gum granulates are exported by external companies.

Part of the communal waste is also dangerous waste, created by different types of batteries, accumulators, light bulb, a mercury switch, etc. Such waste is stocked in particular reservoirs and consequently, special workplaces, orientated to the liquidation of such waste type export the material. In the simulation model given operations are represented by the blocks "Queue - Exit".

Electronic waste is crushed after separation and separated on separation desk to metal, plastic elements and dust, which remains after crushing. Metal and plastic elements are further processed at specialized workplaces. Electronic dust is individually liquidated. This process is represented by connection of several blocks "Queue - Activity - Select item out Exit". 
Inorganic waste that remains in main sorting line is separated on the individual sorting machine to sand fraction $0-8 \mathrm{~mm}$ and $8-64 \mathrm{~mm}$. Separated inorganic waste is exported by external companies for further processing. This process is presented in the simulation model by the block connection "Queue - Activity - Select item out - Exit".

No recycling waste is stored in a reservoir, and it is liquidated in an incinerator, where heat and electric energy is produced. The activity is presented in simulation model by the blocks "Queue - Exit".

The prepared block diagram model of incineration represents the inactive part of the actual computer simulation model. As next, follows the application of a block diagram for this particular simulation system. This application changes the inactive scheme into an active computer simulation model. The output achieved by the implementation of this active simulation model is data that represent the state of the total waste separation and total recycling process.

\subsection{Simulation model design of waste total recycling}

The simulation model of the total waste separation consists of blocks EXTENDSIM (see Fig. 3), which represent the monitored part. Each block of the simulation model has its own meaning and justification. However, not all the operations can be modelled by a one single simulation block. Often a combination of simulation blocks must be used in a sequence corresponding to the real combination of the waste total separation process activities. Consistent parameter setting within the simulation model presents not a less important part of the simulation. The data used for the setting are retrieved from the outcomes of the analysis of the formalized scheme and from the block diagram.

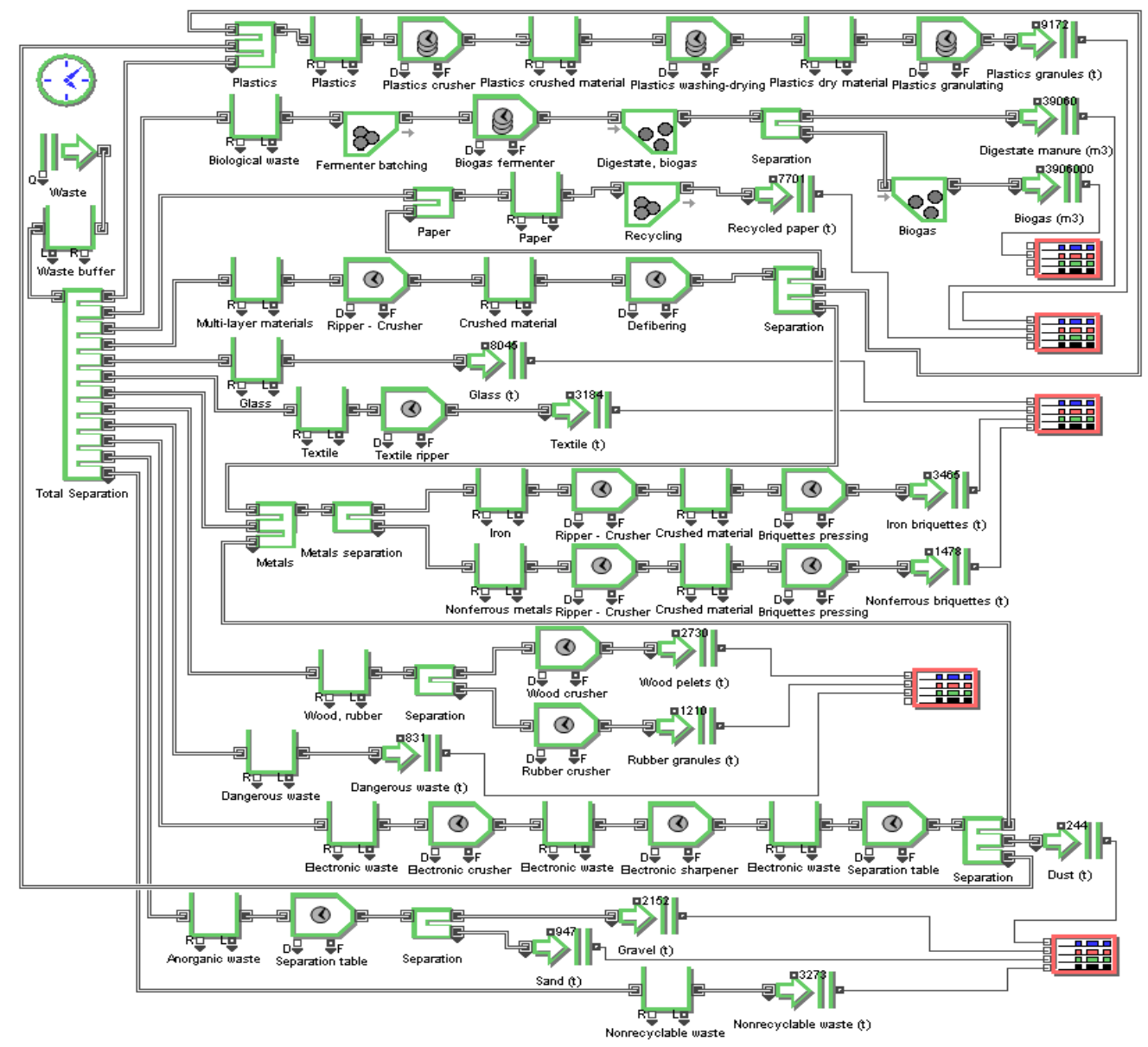

Figure 3: The simulation model of waste total separation, total recycling in EXTENDSIM. 
Parts of the simulation model are characterized by a sequence of blocks that are interconnected by lines that determine the direction of the production flow. Each used block occupies a certain place, located in the simulation model that represents the real studied system. The blocks themselves represent specific processes, facilities or activities that together represent the actual model of the real system of the incineration plant within the case study company (see Fig. 4). Linking the block ensures the creation of flow and enables its management and control. Connecting blocks must represent the real sequence of blocks, as it is in the examined system. By connecting two units via the connectors, a flow line gets created (double or single line) that uniquely defines a sequence of blocks and the direction of flow of requirements and values.

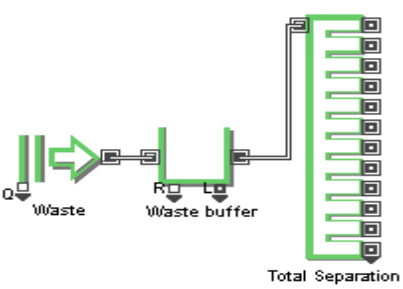

Figure 4: Blocks "Create", "Queue" and "Select item out", which represent the input, storage of waste on the landfill and total separation of waste.

After separation, separated waste is transported to the processing to individual specialized workplaces.

The workplace for plastic processing (see Fig. 5) has a serial ranking of equipment. The output of the workplace is re-granulate, suitable for the production of plastic products, for instance benches, fences, plastic elements, desks, facings, etc.

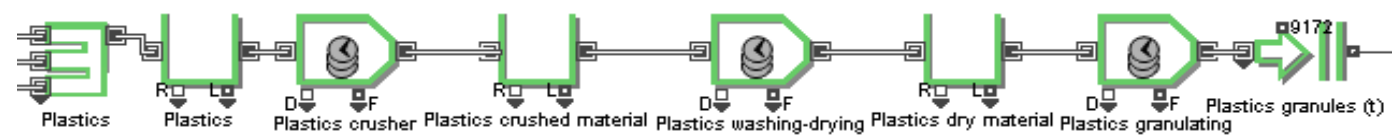

Figure 5: Blocks "Select Item In", "Queue", "Activity" and "Exit" presenting mixing, storing, washing, drying and granulating of the plastics waste material.

The volume of plastic granulate production depends on technology and capacities of production equipment. In given conditions equipment can process three tones of plastic waste per one hour.

The workplace for biologically decomposable waste processing (see Fig. 6) provides ecological processing and liquidation of obtained biomass. The output from the workplace is digestate that is generally used as qualitatively ecological fertilizer and biogas, serving as a source of energy.

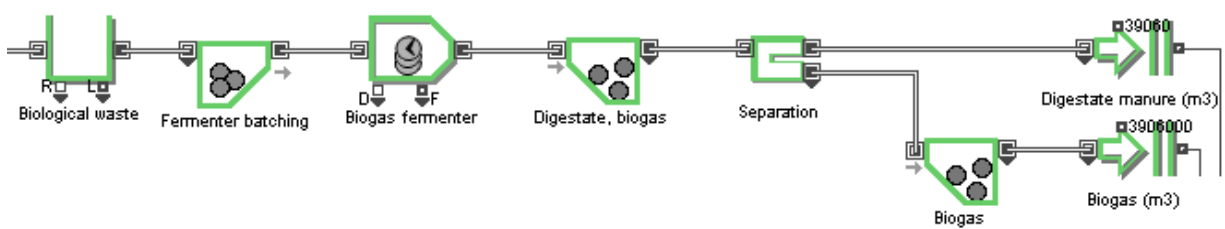

Figure 6: Blocks "Queue", "Batch", “Activity", "Unbatch", "Select Item Out" and "Exit", presenting storing, fermenting, production digestate and biogas of the biologically decomposable waste.

The volume of biogas and digestate production depends on the quality of biomass, obtained from waste. The system is suggested to be able to process the whole volume of biologically decomposable waste, imported in communal waste. The simulation model considers time for biomass processing - mainly 30 days for one batch (see Fig. 7). 


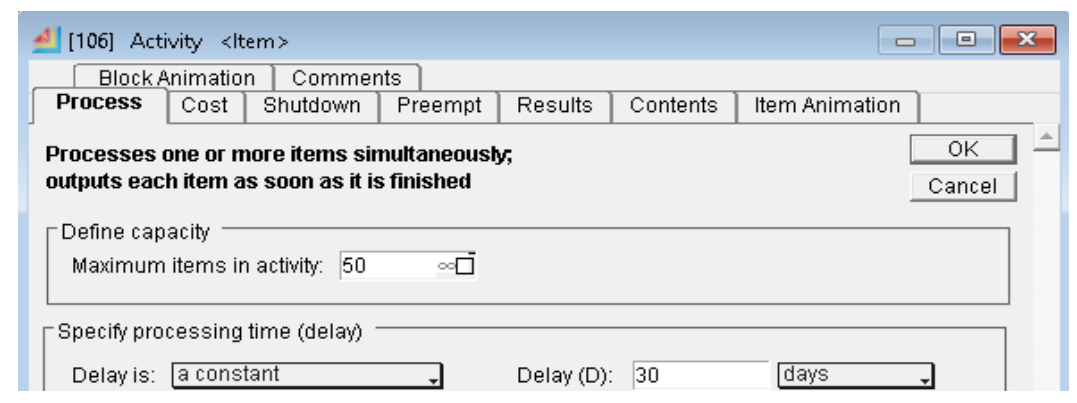

Figure 7: Dialogue of block „Activity“ presenting biomass processing in fermenter according to defined parameters.

The workplace for old paper processing (see Fig. 8) has a serial ranking of equipment. The output of the workplace is recycled paper in the form of paper sheet, reeled in the form of paper rolls. Paper in this form is suitable for further processing, cutting, snipping, etc.

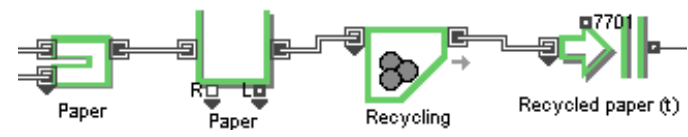

Figure 8: Blocks "Select Item In", "Queue", "Batch" and "Exit", presenting mixing, storing and recycling of the paper waste material.

The workplace needs 1.6 ton of old paper for the production of one ton of recycled paper (see Fig. 9).

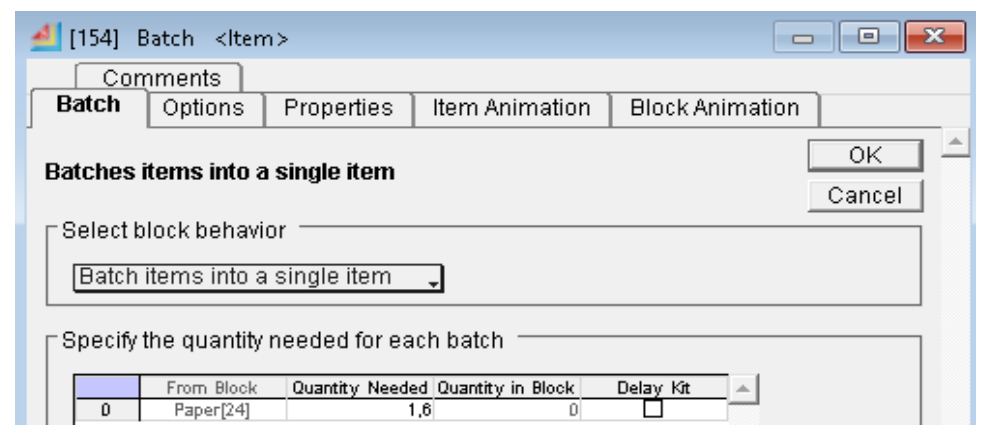

Figure 9: Dialogue of block „Batch“ that represents old paper processing according to defined parameters.

Workplace for multilayer packages processing (see Fig. 10) provides ecologic processing and liquidation of multilayer package materials Tetra Pak ${ }^{\circledR}$. From the given type of packaging, construction elements can also be produced, for instance desks Tetra $\mathrm{K}$ by company Kuruc, etc. Multilayer packages are entirely liquidated in given system by defibering and its separation to plastic, paper and a metal element that are consequently processed in corresponding workplaces.

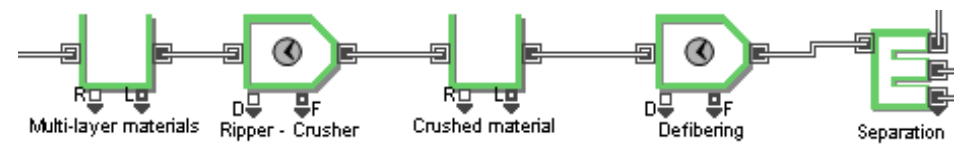

Figure 10: Blocks "Queue", "Activity" and "Select Item Out", presenting storing, crushing, defibering and separating of the multilayer waste material.

The volume of elaborated multilayer packages depends on technology and capacity of production equipment. The system is suggested to be able to process one ton of multilayer packages per two hours. 
As for the volume, multilayer packages are created from $75 \%$ of paper, $20 \%$ plastic (plastic foils) and $5 \%$ metal (metal foils). Separation, sorting and consequent transition of individual elements of multilayer packages to correspondent workplaces is provided by block "Select Item Out" (see Fig. 11).

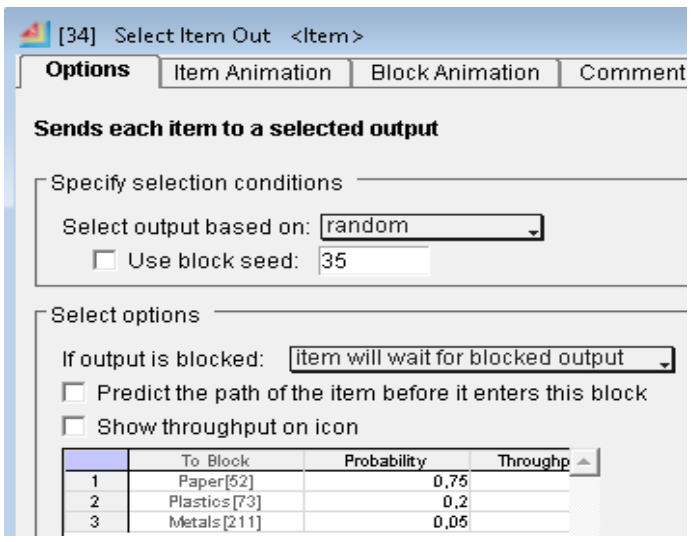

Figure 11: Dialogue of block „Select Item Out“, representing multilayer packages separation according to defined parameters.

All workplaces that present complex system of separation and recycling of communal waste, such as recycling of glass, textile, metals, wood and gum, securing of dangerous waste, electro waste, inorganic waste and no recyclable waste, are projected and set in simulation model by similar way as previous workplaces for elaboration of plastic, biologically decomposable waste, paper and multilayer packages.

\section{RESULTS AND CONCLUSION}

The simulation results show that the suggested complex system of waste recycling in the frame of the searched region can process the yearly production of communal waste. From the economic point of view, waste combustion per sold energy brings approximately 6.046.896 Euro per year. Comparing with prices from the sale of basic raw materials from total waste recycling, it would be possible to obtain 9.344.360 Euro per year (Table I).

If external logistics does not properly work, only a small amount of waste enters processing that could be repeatedly processed into the basic materials. If internal logistics does not properly work, waste accumulation and their landfilling, also in the form of so-called "wild dumps", take place. Only the coordination of external and internal logistics enables operation of total separation and recycling of waste as a source of secondary raw materials. It is necessary to understand that companies that provide the total waste separation can be constructed by minor specialized operations, which are sometimes long away from themselves and therefore waste must be transported among them. The total waste separation must take place in one location, which is followed by the transportation of separated waste to the place of its transformation from its form which is dangerous for living environment into the form of basic material and re-usable raw material (see Fig. 12).

Technologies that enable effective and ecological waste processing are known and available for the market. However, their use is not able without efficient logistics, which is also confirmed by volume of imported waste and the amount of produced raw material for further use in the actual researched system, as well as from simulation model. The research and the simulation show that such complex functional system of total separation and recycling of waste is possible. 
Straka, Khouri, Rosova, Caganova, Culkova: Utilization of Computer Simulation for Waste ...

Table I: Prices of raw materials produced by total recycling in one year period.

\begin{tabular}{|c|c|c|c|}
\hline & Volume/year & Price & Total price/year \\
\hline Plastics granules & $9.000 \mathrm{t}$ & $700,00 € / \mathrm{t}$ & $6.300 .000 €$ \\
\hline Digestate manure & $39.000 \mathrm{t}$ & $5,50 € / \mathrm{t}$ & $214.500 €$ \\
\hline Biogas & $390.000 \mathrm{~m}^{3}$ & $0,29 € / \mathrm{m}^{3}$ & $113.100 €$ \\
\hline Paper & $7.700 \mathrm{t}$ & $50,00 € / \mathrm{t}$ & $385.000 €$ \\
\hline Multilayer materials & $2.400 \mathrm{t}$ & \multicolumn{2}{|c|}{ processing in workplaces plastics, paper, metals } \\
\hline Glass & $8.000 \mathrm{t}$ & $30,00 € / \mathrm{t}$ & $240.000 €$ \\
\hline Textile & $3.000 \mathrm{t}$ & $20,00 € / \mathrm{t}$ & $60.000 €$ \\
\hline Iron briquettes & $3.500 \mathrm{t}$ & $100,00 € / \mathrm{t}$ & $350.000 €$ \\
\hline Nonferrous briquettes & $1.500 \mathrm{t}$ & $700,00 € / \mathrm{t}$ & $1.050 .000 €$ \\
\hline Wood pellets & $2.700 \mathrm{t}$ & $100,00 € / \mathrm{t}$ & $270.000 €$ \\
\hline Rubber granules & $1.200 \mathrm{t}$ & $50,00 € / \mathrm{t}$ & $60.000 €$ \\
\hline Dangerous waste* & $800 \mathrm{t}$ & $160,00 € / \mathrm{t}$ & $-128.000 €$ \\
\hline Electronic waste & $2.400 \mathrm{t}$ & \multicolumn{2}{|c|}{ processing in workplaces plastics, metals } \\
\hline Gravel & $2.100 \mathrm{t}$ & $4,00 € / \mathrm{t}$ & $8.400 €$ \\
\hline Sand & $940 \mathrm{t}$ & $4,00 € / \mathrm{t}$ & $3.760 €$ \\
\hline No recyclable waste & $3.200 \mathrm{t}$ & \multicolumn{2}{|c|}{ counted as price after incineration } \\
\hline Energy after incineration & $29.000 \mathrm{GJ}$ & $14,40 € / \mathrm{GJ}$ & $417.600 €$ \\
\hline Gas for incineration* & $339.200 \mathrm{~m}^{3}$ & $0,29 € / \mathrm{m}^{3}$ & $-98.368 €$ \\
\hline \multicolumn{2}{|l|}{$*$ costs of the company } & TOTAL SUM & $9.344 .360 €$ \\
\hline Energy after incineration & $596.340 \mathrm{GJ}$ & $14,40 € / \mathrm{GJ}$ & $8.587 .296 €$ \\
\hline Gas for incineration* & $87.600 .000 \mathrm{kWh}$ & $0,03 € / \mathrm{kWh}$ & $-2.540 .400 €$ \\
\hline \multicolumn{2}{|l|}{ * costs of the company } & TOTAL SUM & $6.046 .896 €$ \\
\hline
\end{tabular}

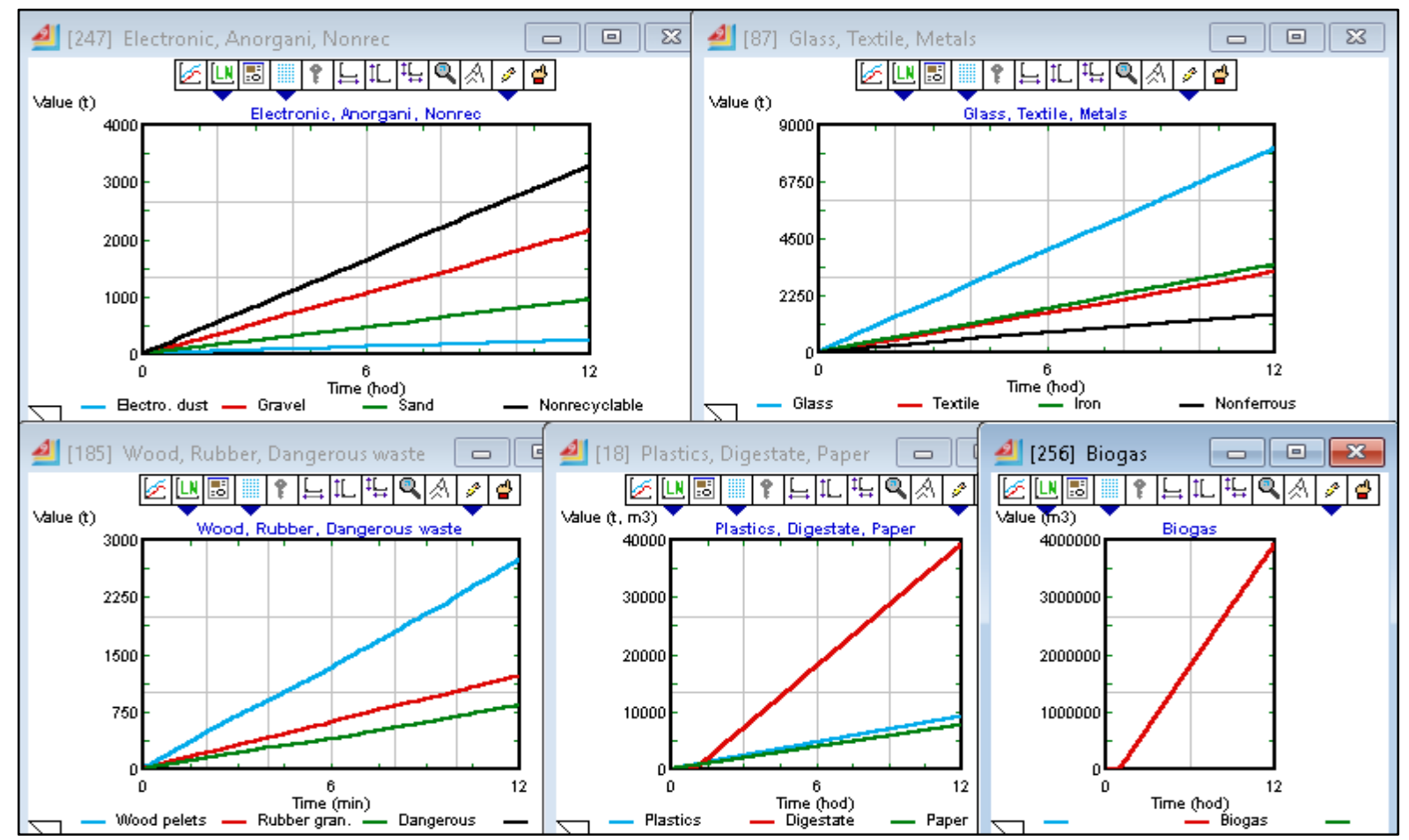

Figure 12: Results of the separated wastes according to the simulation system.

However, from the point of future research, the following questions still remain open:

- How to secure financial support for building complexes for total waste recycling?

- Why does the company not solve waste disposal systematically and globally, but only partially and locally despite being aware of the dangers of environmental waste? 
$\underline{\text { Straka, Khouri, Rosova, Caganova, Culkova: Utilization of Computer Simulation for Waste ... }}$

\section{ACKNOWLEDGEMENT}

The submitted paper is a part of the project "Implementation of innovative instruments for increasing the quality of higher education in the 5.2.52 Industrial Engineering field of study" KEGA 030TUKE4/2017, funded by the Slovak Cultural and Education Grant Agency.

\section{REFERENCES}

[1] Vitasek, K. (2013). CSCMP, CSCMP Glossary, Council of Supply Chain Management Professionals. Definitions compiled by Vitasek, K., from http://cscmp.org/imis0/CSCMP/Educate /SCM_Definitions_and_Glossary_of_Terms/CSCMP/Educate/SCM_Definitions_and_Glossary_o f_Terms.aspx? hkey=60879588-f65f-4ab5-8c4b-6878815ef921, accessed on 29-10-2017

[2] Powell, J. C. (1996). The evaluation of waste management options, Waste Management \& Research, Vol. 14, No. 6, 515-526, doi:10.1177/0734242X9601400601

[3] Strachotová, D.; Zemanová, P.; Botek, M. (2017). Software support for material flow management, Proceedings of Carpatian Logistics Congress (CLC'2017), 72-77

[4] Kumar, S.; Putnam, V. (2008). Cradle to cradle: Reverse logistics strategies and opportunities across three industry sectors, International Journal of Production Economics, Vol. 115, No. 2, 305-315, doi:10.1016/j.ijpe.2007.11.015

[5] Vidalakis, C.; Tookey, J. E. (2006). Conceptual functions of a simulation model for construction logistics, Joint International Conference on Computing and Decision Making in Civil and Building Engineering, 906-915

[6] Matwiejczuk, R. (2015). 2015 Report: Logistics Competences Affecting Business Competitive Advantage Creation, Opole University, Opole

[7] Loučanová, E.; Parobek, J.; Paluš, H.; Kalamárová, M. (2016). Logistics as a part of innovation process, Acta Logistica, Vol. 3, No. 1, 1-4, doi:10.22306/al.v3i1.56

[8] Hur, T.; Lim, S.-T.; Lee, H.-J. A study on the eco-efficiencies for recycling methods of plastics wastes, Presentation, Konkuk University, Dept. of Material Chemistry \& Engineering, LCA Lab., Seoul, from https://slideplayer.com/slide/5943502/, accessed on 09-03-2017

[9] McDougall, F. R.; White, P. R.; Franke, M.; Hindle, P. (2001). Integrated Solid Waste Management: a Life Cycle Inventory, $2^{\text {nd }}$ ed., Blackwell Science, Oxford

[10] Ignácz, P. (2017). Case study of optimisation material replenishment system via principles of logistics, Acta Logistica, Vol. 4, No. 4, 7-10, doi:10.22306/al.v4i4.63

[11] Murray, R. (1999). Creating Wealth from Waste, Demos, London

[12] Vasko, T. (2015). Methods of waste separation in the process of recycling, Technical Journal, Vol. 9, No. 4, 345-351

[13] Ahluwalia, P. K.; Nema, A. K. (2006). Multi-objective reverse logistics model for integrated computer waste management, Waste Management \& Research, Vol. 24, No. 6, 514-527, doi: $10.1177 / 0734242 \times 06067252$

[14] Lomi, A.; Larsen, E. R. (1996). Interacting locally and evolving globally: A computational approach to the dynamics of organizational populations, Academy of Management Journal, Vol. 39, No. 5, 1287-1321, doi: $10.5465 / 257000$

[15] Moss, S.; Edmonds, B. (2005). Sociology and simulation: Statistical and qualitative crossvalidation, American Journal of Sociology, Vol. 110, No. 4, 1095-1131, doi:10.1086/427320

[16] Davidsson, P.; Persson, J. A.; Holmgren, J. (2007). On the integration of agent-based and mathematical optimization techniques, Nguyen, N. T.; Grzech, A.; Howlett, R. J., Jain, L. C. (Eds.), Agent and Multi-Agent Systems: Technologies and Applications, KES-AMSTA 2007, Lecture Notes in Computer Science, Vol. 4496, Springer, Berlin, 1-10, doi:10.1007/978-3-54072830-6_1

[17] Bohács, G.; Rinkács, A. (2017). Development of an ontology-driven, component based framework for the implementation of adaptiveness in a Jellyfish-type simulation model, Journal of Ambient Intelligence and Smart Environments, Vol. 9, No. 3, 361-374, doi:10.3233/ais-170437

[18] Plavac, B.; Filipan, V.; Sutlovic, I.; Sveticic, J. (2017). Sustainable waste management with mechanical biological treatment and energy utilization, Technical Gazette, Vol. 24, No. 4, 1283 1289, doi: $10.17559 / \mathrm{TV}-20150709113428$ 
[19] Delgado Sobrino, D. R.; Koštál, P.; Cagáňová, D.; Čambál, M. (2013). On the Possibilities of Intelligence Implementation in Manufacturing: The Role of Simulation, Applied Mechanics and Materials, Vol. 309 (selected papers from the $3^{\text {rd }}$ Central European Conference on Logistics CECOL 2012), 96-104, doi:10.4028/www.scientific.net/AMM.309.96

[20] Kliment, M.; Trebuňa, P. (2014). Simulation as an appropriate way of verifying the efficiency of production variants in the design of production and non-production systems, Acta Logistica, Vol. 1, No. 4, 17-21, doi:10.22306/al.v1i4.27

[21] Sauvageau, G.; Frayret, J.-M. (2015). Waste paper procurement optimization: An agent-based simulation approach, European Journal of Operational Research, Vol. 242, No. 3, 987-998, doi:10.1016/j.ejor.2014.10.035

[22] Wicher, P; Staš, D.; Karkula, M.; Lenort, R.; Besta, P. (2015). A computer simulation-based analysis of supply chains resilience in industrial environment, Metalurgija, Vol. 54, No. 4, 703706

[23] Drastich, A. (2017). Optimization of material flow by simulation methods, Acta Logistica, Vol. 4, No. 4, 23-26, doi:10.22306/al.v4i4.76

[24] Bala, B. K. (1991). System dynamics modelling and simulation of biogas production systems, Renewable Energy, Vol. 1; No. 5-6, 723-728, doi:10.1016/0960-1481(91)90019-L

[25] Malindzak, D. (2010). Models and simulation in logistics, Acta Montanistica Slovaca, Vol. 15, Special Issue 1, 1-3

[26] Witkowski, J.; Kiba-Janiak, M. (2014). The role of local governments in the development of city logistics, Procedia - Social and Behavioral Sciences, Vol. 125, 373-385, doi:10.1016/ j.sbspro.2014.01.1481

[27] Straka, M.; Malindzakova, M.; Trebuna, P.; Rosova, A.; Pekarcikova, M.; Fill, M. (2017). Application of EXTENDSIM for improvement of production logistics' efficiency, International Journal of Simulation Modelling, Vol. 16, No. 3, 422-434, doi:10.2507/IJSIMM16(3)5.384

[28] Wang, Y. R.; Chen, A. N. (2016). Production logistics simulation and optimization of industrial enterprise based on Flexsim, International Journal of Simulation Modelling, Vol. 15, No. 4, 732741, doi:10.2507/IJSIMM15(4)CO18

[29] Brem, G.; Gort, R.; van Kessel, L. B. M. (1992). Theoretical and experimental modelling of municipal solid waste incineration, $7^{\text {th }}$ International Recycling Congress, 201-213

[30] Malindzakova, M.; Straka, M.; Rosova, A.; Kanuchova, M.; Trebuna, P. (2015) Modeling the process for incineration of municipal waste, Przemysl Chemiczny, Vol. 94, No. 8, 1260-1264, doi:10.15199/62.2015.8.4

[31] Straka, M. (2017). The theoretical starting point of simulation - simulation system EXTENDSIM 9.x., Technical University of Kosice, Kosice (in Slovak)

[32] Knapčíková, L.; Dupláková, D.; Radchenko, S.; Hatala, M. (2017). Rheological behavior modelling of composite materials used in engineering industry, TEM Journal, Vol. 6, No. 2, 242245, doi:10.18421/TEM62-07

[33] Nikakhtar, A.; Hosseini, A. A.; Wong, K.Y.; Zavichi, A. (2015). Application of lean construction principles to reduce construction process waste using computer simulation: a case study, International Journal of Services and Operations Management, Vol. 20, No. 4, 461-480, doi:10.1504/IJSOM.2015.068528

[34] Kleijnen, J. P. C. (2005). Supply chain simulation tools and techniques: a survey, International Journal of Simulation and Process Modelling, Vol. 1, No. 1/2, 82-89, doi:10.1504/ IJSPM.2005.007116 